\title{
Differential Regulation of Two Types of Intracellular Calcium Release Channels during End-Stage Heart Failure
}

\author{
Loewe O. Go, Maria C. Moschella, James Watras," Kushal K. Handa, Billie S. Fyfe, ${ }^{\ddagger}$ and Andrew R. Marks \\ Molecular Medicine Program and Division of Cardiology, Department of Medicine, and ${ }^{\ddagger}$ Department of Pathology, Mount Sinai \\ School of Medicine, New York 10029; and *Departments of Medicine and Physiology, University of Connecticut, Farmington, \\ Connecticut 06032
}

\begin{abstract}
The molecular basis of human heart failure is unknown. Alterations in calcium homeostasis have been observed in failing human heart muscles. Intracellular calcium-release channels regulate the calcium flux required for muscle contraction. Two forms of intracellular calcium-release channels are expressed in the heart: the ryanodine receptor (RyR) and the inositol 1,4,5-trisphosphate receptor (IP3R). In the present study we showed that these two cardiac intracellular calcium release channels were regulated in opposite directions in failing human hearts. In the left ventricle, RyR mRNA levels were decreased by $31 \%(P<0.025)$ whereas IP3R mRNA levels were increased by $123 \%(P<0.005)$. In situ hybridization localized both RyR and IP3R mRNAs to human cardiac myocytes. The relative amounts of IP3 binding sites increased $\sim 40 \%$ compared with ryanodine binding sites in the failing heart. RyR down-regulation could contribute to impaired contractility; IP3R up regulation may be a compensatory response providing an alternative pathway for mobilizing intracellular calcium release, possibly contributing to the increased diastolic tone associated with heart failure and the hypertrophic response of failing myocardium. (J. Clin. Invest. 1995. 95:888-894.) Key words: ryanodine receptor $\bullet$ inositol 1,4,5-trisphosphate receptor • calcium channel $\cdot$ excitation-contraction coupling $\bullet$ congestive heart failure
\end{abstract}

\section{Introduction}

Congestive heart failure (CHF) ${ }^{1}$ affects more than 2.3 million people in the United States. Approximately 400,000 new cases

Address correspondence to Andrew R. Marks, M.D., Molecular Medicine Program, Box 1269, Mount Sinai School of Medicine, One Gustave L. Levy Place, New York, NY 10029. Phone: 212-241-0309; FAX: 212-996-4498.

Received for publication 28 July 1994 and in revised form 31 October 1994.

1. Abbreviations used in this paper: CHF, congestive heart failure; ICM, ischemic cardiomyopathy; IDCM, idiopathic dilated cardiomyopathy; IP3R, inositol 1,4,5-trisphosphate receptor; LV, left ventricle; RV, right ventricle; RyR, ryanodine receptor.

J. Clin. Invest.

(c) The American Society for Clinical Investigation, Inc.

0021-9738/95/02/0888/07 $\$ 2.00$

Volume 95, February 1995, 888-894 are diagnosed each year, and mortality is substantial with $200,000-400,000$ deaths per year (1). The risk of death increases with worsening clinical class; patients in New York Heart Association class IV CHF have a 50-60\% one-year mortality (2). The magnitude of these numbers underscores the importance of elucidating the mechanisms underlying myocardial dysfunction in end-stage CHF in order to provide a framework for future diagnostic and therapeutic approaches.

Excitation-contraction coupling in the heart requires the activation of the calcium-release channel in the sarcoplasmic reticulum (SR) (3). Calcium influx via the voltage gated calcium channel of the transverse tubule triggers the release of calcium from the SR into the cytosol via the ryanodine receptor (RyR)/ calcium-release channel. This phenomenon is referred to as calcium-induced calcium release $(4,5)$. Cytosolic calcium binding to troponin $\mathrm{C}$ activates the contractile apparatus.

A second type of calcium-release channel has been identified on the endoplasmic reticulum of rodent brain and smooth muscle $(6,7)$, and most recently in rodent myocardium $(8)$. This channel is activated by IP3, a ubiquitous second messenger ( 9 , 10). IP3 generated by phosphoinositide hydrolysis binds to its intracellular receptor, a calcium release channel on the endoplasmic reticulum that is structurally related to the RyR. This type of activation of intracellular calcium release, which stimulates among other things smooth muscle contraction, is referred to as pharmacomechanical coupling (11-13).

The structures of the cardiac RyR and the type 1 inositol 1,4,5-trisphosphate receptor (IP3R) have been determined by cDNA cloning. The RyR and IP3R are tetramers comprised of four $565-\mathrm{kD}$ subunits $(14-16)$, and four $313-\mathrm{kD}(6,7,17)$, respectively. They are members of a gene family that comprises the largest channel structures identified to date.

Abnormal calcium homeostasis has been demonstrated in failing human myocardium (18). Previous studies found that mRNA levels of the SR calcium-ATPase and DHPR were decreased in end-stage human CHF $(19,20)$. Recent work has demonstrated that mRNA levels of the RyR were also reduced in the myopathic left ventricle compared with normal $(21,22)$.

To date, IP3R mRNA levels in normal and failing human hearts have not been described. Indeed it is only recently that IP3R expression in the heart has been appreciated. The decreased mRNA levels of the excitation-contraction coupling calcium channels during CHF (19-22) and the possibility that neurohormonal activation could regulate cardiac contractility (23), led us to compare RyR and IP3R mRNA levels in failing human hearts. We reasoned that pharmacomechanical coupling might assume a more important role in regulating calcium homeostasis during CHF. The goals of the present study, therefore, 
were to determine: $(a)$ whether the IP3R is expressed in the human myocardium, and $(b)$ whether the levels of IP3R are regulated during CHF in the same manner as the RyR.

\section{Methods}

Clinical data. For each of the 32 patients, the pretransplant medical record was reviewed to determine the clinical diagnosis, ejection fraction (based on echocardiography or radionuclide angiography), hemodynamic parameters obtained as part of transplant evaluation (cardiac index, pulmonary capillary wedge pressure, pulmonary vascular resistance index), and medications taken within the 2-mo period before transplantation.

Harvesting of tissue and RNA preparation. This study was conducted with the approval of the institutional review board at Mount Sinai Medical Center. Explanted hearts were obtained prospectively in the operating room from 32 patients who underwent cardiac transplantation at our center between April 28, 1992 and January 22, 1994. Tissue sections weighing $\sim 2$ grams were harvested from the left anterolateral ventricle (LV), right ventricular free wall (RV), and ventricular septum of each heart. Scar tissue was avoided as much as possible during sampling. Sections from six normal LV and five normal RV and septa were also collected as control tissue. (Sources of normal tissue were trauma victims who had not consented for organ donation and potential donors rejected due to underlying systemic diseases.) Samples. were immediately flash frozen in liquid nitrogen and stored at $-80^{\circ} \mathrm{C}$ until use. Total RNA was isolated from these samples after homogenization, using the standard guanidinium isothiocyanate lysis method followed by centrifugation over a cesium chloride cushion (14).

Northern and slot blot analysis. Purified RNA (20 $\mu \mathrm{g})$ was sizefractionated on formaldehyde/agarose gels and transferred onto nitrocellulose filters overnight using 10X SSC (1X SSC $=0.15 \mathrm{M} \mathrm{NaCl} / 0.015 \mathrm{M}$ sodium citrate, $\mathrm{pH} 7.0)$. Total RNA $(12.5,5$, and $2.5 \mu \mathrm{g})$ was loaded onto a slot blot apparatus (GIBCO BRL, Gaithersburg, MD). Filters were then baked at $80^{\circ} \mathrm{C}$ for $2 \mathrm{~h}$ in a vacuum oven and prehybridized at $42^{\circ} \mathrm{C}$ overnight in buffer with $1 \mathrm{X}$ Denhardt's solution $(0.02 \%$ polyvinylpyrrolidone $/ 0.02 \%$ Ficoll/0.02\% bovine serum albumin), $5 \mathrm{X}$ SSC, $0.025 \mathrm{M}$ sodium phosphate (pH 7.4), sonicated calf thymus DNA (50 $\mathrm{mg} / \mathrm{ml}$ ), $0.1 \%$ SDS, and $50 \%$ (vol/vol) formamide. The filters were hybridized to cDNA probes overnight at $42^{\circ} \mathrm{C}$ in the same buffer mixture followed by washing in $0.2 \mathrm{X} \mathrm{SSC}$ at $55^{\circ} \mathrm{C}$ for $15 \mathrm{~min}$ (22). Filters were exposed on a Storage Phosphor Screen and on $\mathrm{x}$-ray film at $-80^{\circ} \mathrm{C}$ with a single intensifying screen. The presence of a single band on northern blot analysis for each of the mRNAs examined permitted further quantification by slot blot analysis. Relative amounts of mRNA were determined with the Phosphorimager using Imagequant software.

cDNA probes. Two cDNA probes were used for Northern and slot blot analyses: HCRC1 - a 580 bp EcoRI and BamHI fragment corresponding to nucleotides 5027-5647 of the rabbit cardiac RyR cDNA (22); and R-IP3R1 - a 1.7-kb EcoRI fragment of rat aortic smooth muscle cDNA corresponding to nucleotides $987-2705$ of rat brain IP3R cDNA sequence (8). All cDNA probes were uniformly labeled with random primers using Klenow and $\alpha-P^{32}$ dCTP to a specific activity of $>10^{9} \mathrm{cpm} / \mu \mathrm{g}$. Tissue distribution and specificity of these cDNA probes were assessed using rabbit tissue Northern blots. For internal control and normalization of mRNA Phosphorimager scores, a synthetic $28 \mathrm{~S}$ cDNA oligonucleotide based on the human $28 \mathrm{~S}$ ribosomal RNA sequence was used after exchange labeling with polynucleotide kinase and $\gamma$ - $\mathrm{P}^{32}$ ATP.

In situ hybridization. Tissue samples from human hearts were fixed in 4\% paraformaldehyde in $0.1 \mathrm{M}$ PBS overnight, cryoprotected in 0.5 and $1 \mathrm{M}$ sucrose in $0.1 \mathrm{M}$ PBS for $30-45 \mathrm{~min}$, and then frozen in CryoEmbed compound in liquid nitrogen and stored at $-80^{\circ} \mathrm{C}$ until use. 10 $\mu \mathrm{m}$ thick sections were obtained by using an IBHI cryostat and collected onto coated slides. Sections were refixed with paraformaldehyde for 20 $\mathrm{min}$, incubated for $30 \mathrm{~min}$ with proteinase $\mathrm{K}(3 \mathrm{mg} / \mathrm{ml}$ in $0.1 \mathrm{M}$ Tris, pH $7.5 ; 0.01 \mathrm{M}$ EDTA), in $0.2 \mathrm{M} \mathrm{HCl}$ for $20 \mathrm{~min}$, and treated with acetic anhydride $(0.25 \%$ in $0.1 \mathrm{M}$ triethanolamine buffer, $\mathrm{pH} 8.0)$ for $10 \mathrm{~min}$ at room temperature. Three million $\mathrm{cpm}$ of sense and antisense cRNA [ ${ }^{35}$ S $]$ CTP-labeled probes, transcribed from linearized HCRC1 and R-IP3R1 cDNA, were applied to individual slides. Hybridization was performed in $50 \%$ formamide, $0.3 \mathrm{M} \mathrm{NaCl}, 10 \%$ dextran sulfate, $2 \mathrm{mM}$ EDTA, 1X Denhardt's, 0.01 M Tris HCl, pH 8, 0.05 M DTT for 16$20 \mathrm{~h}$. Washing conditions included $2 X$ SSPE in presence of $10 \mathrm{mM}$ DTT for $1 \mathrm{~h}$ at room temperature followed by treatment with $20 \mathrm{mg} /$ $\mathrm{ml}$ RNase in $4 X$ SSPE and $10 \mathrm{mM}$ DTT for $30 \mathrm{~min}$ at $37^{\circ} \mathrm{C}$. Slides were further washed at $60^{\circ} \mathrm{C}$ for $1 \mathrm{~h}$ in $50 \%$ formamide, $2 \mathrm{X}$ SSPE and $10 \mathrm{mM}$ DTT, transferred to $0.3 \mathrm{M}$ ammonium acetate and $1 \%$ glycerol before dipping in NTB2 autoradiographic emulsion. Slides were developed in Kodak D-19 (Eastman Kodak Co., Rochester, NY) after 2wk exposures. Specimens were photographed using a Zeiss Axiophot microscope equipped with a darkfield condenser (8).

Radioligand binding assays. $50 \mu \mathrm{g}$ of membranes were incubated in appropriate conditions: (a) ryanodine binding $-37^{\circ} \mathrm{C}$ for $1 \mathrm{~h}$ with 10 $\mathrm{mM}\left[{ }^{3} \mathrm{H}\right]$ ryanodine in buffer $\left(0.5 \mathrm{M} \mathrm{KCl}, 5 \mathrm{mM}\right.$ Hepes, $0.1 \mathrm{mM} \mathrm{CaCl}_{2}$, $10 \mathrm{mM}$ ATP, pH 7.4) (24); (b) IP3 binding - on ice for 10 min with $10 \mathrm{mM}\left[{ }^{3} \mathrm{H}\right] \mathrm{IP} 3$ in buffer $(0.1 \mathrm{M} \mathrm{NaCl}, 5 \mathrm{mM}$ Hepes, $1 \mathrm{mM}$ EGTA, 1 mM DTT, 2 mM EDTA, pH 8.3) (25). Bound radioactivity was pelleted by ultracentrifugation and measured using a liquid scintillation counter. Nonspecific binding was measured by incubating with a $>100$-fold excess of the respective unlabeled ligand, and specific binding calculated as total minus nonspecific binding.

Statistical analysis. All data are expressed as mean \pm standard error (SE). Differences were assessed with the use of unpaired two-tailed Student's $t$ test and considered significant if $P<0.05$.

\section{Results}

Clinical and hemodynamic characteristics of patients. The clinical diagnosis of the 32 cardiac transplant patients were as follows: 15 had ischemic cardiomyopathy (ICM), 14 had idiopathic dilated cardiomyopathy (IDCM), 2 had hypersensitivity myocarditis, and 1 had sarcoidosis. The clinical and pretransplant hemodynamic characteristics of the patients are listed in Table I. There were 22 males and 10 females, and the mean age was $47 \pm 2.3 \mathrm{yr}$. The degree of heart failure in this group of patients was severe as gauged by ejection fraction $(14 \pm 1.1 \%)$, cardiac index $\left(2.2 \pm 0.1 \mathrm{lier} / \mathrm{min}\right.$ per $\left.\mathrm{m}^{2}\right)$, pulmonary capillary wedge pressure $(23 \pm 1.7 \mathrm{~mm} / \mathrm{Hg})$, and pulmonary vascular resistance index $\left(5.5 \pm 0.5\right.$ Wood units- $\left.\mathrm{m}^{2}\right)$. Within the two months before transplantation, all patients were taking digoxin, diuretics, angiotensin-converting enzyme inhibitors, and antithromboticl anticoagulant medications. 22 patients were on intravenous positive inotropes and six patients were on $\beta$-adrenergic blockers at the time of transplantation. None of the patients were taking calcium channel blockers.

Tissue distribution and specificity of cDNA probes. Northern blot analysis of rodent tissue RNA hybridized to either the HCRC-1 or R-IP3R1 cDNA probe is shown in Fig. 1. HCRC1 identified a single $\sim 16-\mathrm{kb}$ mRNA species representing the cardiac isoform of the RyR in both rabbit heart and brain; no signals were detected in skeletal muscle, uterus, and kidney (the latter two rich in smooth muscle tissue). On the other hand, RIP3R1 identified a single $\sim 10-\mathrm{kb}$ mRNA species representing the type 1 isoform of the IP3R in all rodent tissues except skeletal muscle. The signal was strongest in rat heart, intermediate in rabbit brain, and weakest in rabbit uterus and kidney. Nonspecific hybridization (e.g., to ribosomal RNAs) was not observed.

Calcium-release channel mRNA levels in human hearts. When human myocardial RNA was subjected to Northern blot 
Table I. Clinical Characteristics of Patients with End-Stage Heart Failure

\begin{tabular}{|c|c|c|c|c|c|c|}
\hline Patient & Age & Sex & $\mathrm{EF}$ & $\mathrm{CI}$ & PCWP & PVRI \\
\hline & & & $\%$ & $\nu / \min / m^{2}$ & $m m \mathrm{Hg}$ & Wood $U / m^{2}$ \\
\hline 1 & 64 & $\mathbf{M}$ & 18 & 2.1 & 26 & 4.7 \\
\hline 2 & 45 & $\mathbf{M}$ & & 2.1 & 14 & 8.1 \\
\hline 3 & 52 & $\mathbf{M}$ & 15 & 2.6 & 18 & 8.3 \\
\hline 4 & 58 & $\mathbf{M}$ & & 2.2 & 26 & 6.6 \\
\hline 5 & 42 & $\mathbf{M}$ & 4 & 2.1 & 26 & 6.2 \\
\hline 6 & 48 & $\mathbf{M}$ & 6 & 2 & 29 & 5.5 \\
\hline 7 & 51 & $\mathbf{F}$ & 12 & 1.8 & 29 & 6 \\
\hline 8 & 59 & $F$ & 20 & 1.6 & 18 & 5 \\
\hline 9 & 45 & $\mathbf{M}$ & 9 & 1.9 & 30 & 5.6 \\
\hline 10 & 46 & $\mathbf{F}$ & 15 & 1.6 & 23 & 7.5 \\
\hline 11 & 62 & $\mathbf{M}$ & & 2.1 & 42 & 4.8 \\
\hline 12 & 52 & $\mathbf{M}$ & 11 & 2.1 & 33 & 4.8 \\
\hline 13 & 56 & $\mathbf{F}$ & 10 & 2.6 & 6 & 3.1 \\
\hline 14 & 39 & $\mathbf{M}$ & 14 & 3.7 & 10 & 1.9 \\
\hline 15 & 45 & $\mathbf{M}$ & 20 & 1.9 & 9 & 5.3 \\
\hline 16 & 45 & $\mathbf{M}$ & 22 & 2.4 & 9 & 3.3 \\
\hline 17 & 60 & $\mathrm{~F}$ & 14 & 2.2 & 23 & 5.4 \\
\hline 18 & 58 & $\mathbf{F}$ & 15 & 1.9 & 38 & 3.6 \\
\hline 19 & 63 & $\mathbf{F}$ & 15 & 2.6 & 26 & 3.5 \\
\hline 20 & 59 & $\mathbf{M}$ & & 2.6 & 27 & 3.5 \\
\hline 21 & 14 & $\mathbf{M}$ & 10 & 1 & 30 & 5 \\
\hline 22 & 13 & $\mathbf{M}$ & 5 & 2 & 28 & 5.6 \\
\hline 23 & 54 & $\mathbf{M}$ & 15 & 1.8 & 38 & 8.7 \\
\hline 24 & 63 & $\mathbf{M}$ & & 1.6 & 30 & 3.8 \\
\hline 25 & 43 & $\mathbf{F}$ & 16 & 3 & 20 & 3.3 \\
\hline 26 & 48 & $\mathbf{M}$ & & 1.9 & 18 & 4.7 \\
\hline 27 & 45 & $\mathbf{M}$ & 16 & 2.4 & 8 & 16.9 \\
\hline 28 & 42 & $\mathbf{M}$ & 9 & 1.8 & 23 & 6.8 \\
\hline 29 & 18 & $\mathbf{M}$ & 24 & 1.4 & 34 & 9 \\
\hline 30 & 40 & $\mathrm{~F}$ & 23 & 3.6 & 16 & 2.2 \\
\hline 31 & 43 & $\mathbf{M}$ & 6 & 2.4 & 16 & 3.3 \\
\hline 32 & 45 & $\mathrm{~F}$ & 15 & 2.5 & 8 & 3.2 \\
\hline Mean $\pm S E$ & $47 \pm 2.3$ & & $14 \pm 1.1$ & $2.2 \pm 0.1$ & $23 \pm 1.7$ & $5.5 \pm 0.5$ \\
\hline
\end{tabular}

$E F$, ejection fraction; $C I$, cardiac index; $P C W P$, pulmonary capillary wedge pressure; $P V R I$, pulmonary vascular resistance index; $I C M$, ischemic cardiomyopathy; IDCM, idiopathic dilated cardiomyopathy; $S E$, standard error.

analysis with the same cDNA probes, HCRC1 detected a single $\sim$ 16-kb RyR mRNA while R-IP3R1 recognized a distinct $\sim$ 10-kb IP3R mRNA; no other signals were detected. Fig. 2 shows representative lanes from Northern blot analysis of RNA prepared from the different regions of normal and failing human ventricles, hybridized to probes for the cardiac RyR, aortic smooth muscle IP3R, and 28S. In both normal and cardiomyopathic tissue, the RyR mRNA was much more abundant than IP3R mRNA in all regions. However, the intensity of the mRNA signals varied according to the region from which it was taken, the amount of RNA present as indicated by the $28 \mathrm{~S}$ ribosomal RNA signal, and whether or not the tissue was cardiomyopathic. To quantify these signals more precisely, slot blot analysis was performed.

Results of quantitative slot blot analysis of human myocardial RNA using HCRCl probe are summarized in Fig. $3 A$.
A

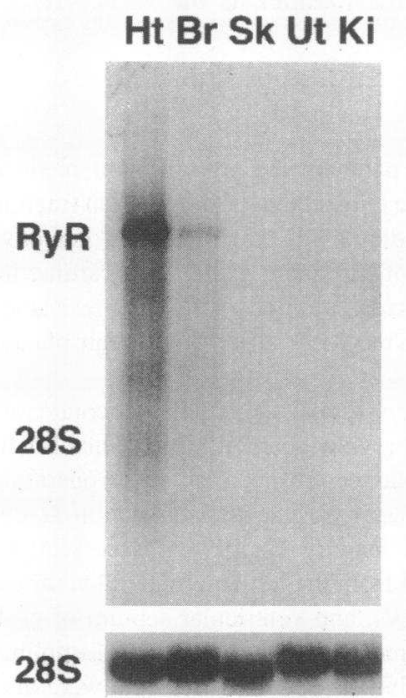

B

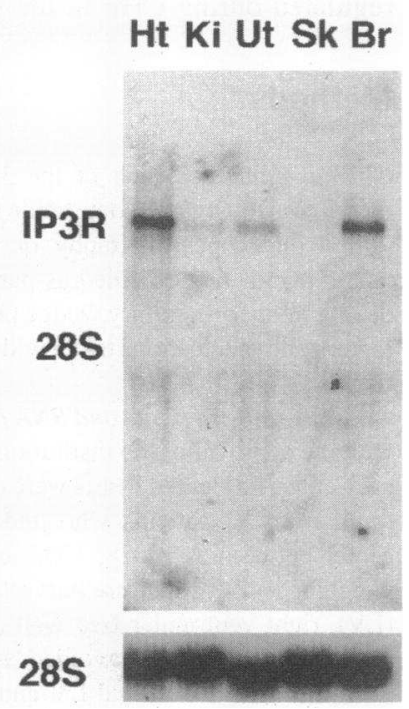

Figure 1. Northern blot analysis demonstrating specificity and tissue distribution of cDNA probes. $20 \mu \mathrm{g}$ of total RNA isolated from rabbit brain $(\mathrm{Br})$, mixed skeletal muscle (Sk), uterus (Ut), kidney $(\mathrm{Ki})$, and either rabbit or rat heart $(\mathrm{Ht})$ tissue was subjected to formaldehyde/ agarose gel electrophoresis, transferred to nitrocellulose filters, and hybridized to random-labeled cDNA probes. The $28 \mathrm{~S}$ RNA is shown as size marker. (A) HCRC1 identified a single $\sim 16-\mathrm{kb}$ mRNA species representing the cardiac isoform of the RyR in both rabbit heart and brain; no signals were detected in skeletal muscle, uterus, and kidney. (B) On this blot, $\mathrm{Ht}$ represents rat heart, while the rest represent rabbit tissues. R-IP3R1 identified a single $\sim$ 10-kb mRNA species representing the type 1 isoform of the IP3R in all tissues except skeletal muscle. The signal was strongest in heart, intermediate in brain, and weakest in uterus and kidney.

Consistent with previous findings (22), cardiac RyR mRNA levels were reduced in the $\mathrm{LV}$ of cardiomyopathic patients by $31 \%(P<0.025)$ compared with normals. Cardiac RyR mRNA levels were also decreased in the septum of cardiomyopathic patients by $37 \%(P<0.05)$ compared with normals. The differences were significant in subgroup comparisons of normal patients with ICM and IDCM patients (data not shown). In the

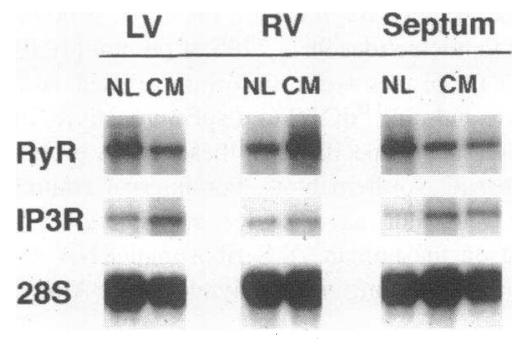

Figure 2. Representative Northern blot analysis of calcium-release channel mRNA expression in normal and myopathic human heart tissue. 20 $\mu \mathrm{g}$ of total RNA prepared from different regions of the heart obtained from normal (NL) patients and patients with cardiomyopathy (CM) was size-fractionated on formaldehyde/agarose gels and blotted to nitrocellulose filters. For each region, the same blot was used to hybridize with each random-labeled cDNA probe at separate times. Blots were exposed to $\mathrm{x}$-ray films for either 1 wk (R-IP3R1) or $3 \mathrm{~d}$ (HCRC1). The $28 \mathrm{~S}$ ribosomal RNA is shown as a measure of total RNA loading. In all samples, the HCRC1 probe detected the $\sim 16-\mathrm{kb}$ RyR mRNA while the R-IP3R1 probe recognized the $\sim 10-k b$ IP3R mRNA. 


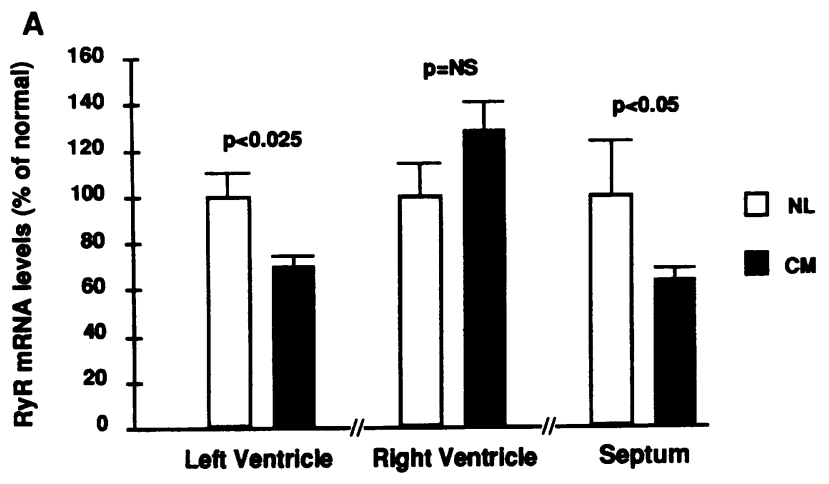

sites were decreased by $30 \%$ in the myopathic LV $(n=4)$ compared with normals $(n=3)$, but the level of $\left[{ }^{3} \mathrm{H}\right] \mathrm{IP} 3$ binding sites $(n=4)$ was unchanged compared to normals $(n=3)$.

Localization of calcium-release channel mRNA in cardiac myocytes. The myocardium is comprised of multiple cell types (e.g., cardiac myocytes, vascular smooth muscle cells, endothelial cells), all of which could express and potentially regulate RyR and IP3R channels. To determine the cellular location of the mRNA signals, in situ hybridization was performed on a subset of normal and myopathic tissue sections. Fig. 4 shows representative results of in situ hybridization using specific cRNA probes on the myopathic LV. Hybridization with the IP3R antisense probe demonstrated that the IP3R mRNA is present not only in the vascular smooth muscle surrounding intramyocardial arteries, but also within the cardiac myocytes in a patchy distribution (Fig. $4 \mathrm{C}$ ); higher magnification revealed that the patchy appearance was due to clustering of granules within pleomorphic nuclei. Adjacent sections hybridized with sense probe did not show signals above background distribution as expected (data not shown). In situ hybridization using cardiac RyR antisense probe revealed abundant RyR mRNA signals within cardiac myocytes, but not in vascular smooth muscle cells (Fig. 4 D).

\section{Discussion}

The present study demonstrates that: (a) two different types of calcium-release channels are expressed in the normal and failing human myocardium - the RyR and the IP3R, and (b) distinct and opposite regulation of each type of calcium-release channel mRNA occurs during end-stage CHF.

Although the dominant mechanism of excitation-contraction coupling in cardiac muscle is calcium-induced calcium release via the $\operatorname{RyR}(4,5)$, evidence has accumulated supporting a role for IP3-induced calcium release as well. Functional studies on isolated animal ventricular fibers have shown that IP3 triggers calcium release from the SR (26) and potentiates the effects of caffeine-induced calcium release (27). Northern blot analyses using the cloned murine IP3R cDNA as a probe have identified the $\sim 10-\mathrm{kb}$ IP3R mRNA in various mouse tissues, including the heart $(7,28)$. Recently, our laboratory showed that the IP3R is expressed in rat cardiac myocytes by immunohistochemistry and in situ hybridization (8). Using Northern blot analysis and in situ hybridization in the present study, we have now conclusively demonstrated that the IP3R mRNA is also expressed in both normal and diseased human cardiac myocytes, albeit in relatively low amounts compared with the RyR (Fig. 2 and 4).

Previous studies on human CHF have demonstrated down regulation of the mRNAs encoding the excitation-contraction coupling calcium channels in myopathic LV tissue. The mRNA level of SR calcium-ATPase has been shown to be reduced by 35-55\% in end-stage CHF (19-22). Likewise, mRNA levels of the voltage gated calcium channel DHPR were decreased in myopathic LV by $47 \%$ (20). Our group and others have also shown that RyR mRNA expression in the LV was decreased in cardiomyopathy patients $(21,22)$.

The current study extends these observations. Not only was RyR mRNA level in the LV decreased by $29 \%$ in ICM patients $(P<0.05)$, but it was also reduced by $32 \%$ in IDCM patients $(p<0.05)$. Cardiac RyR mRNA levels were also reduced in myopathic septum by $36-39 \%(P<0.05)$, regardless of 

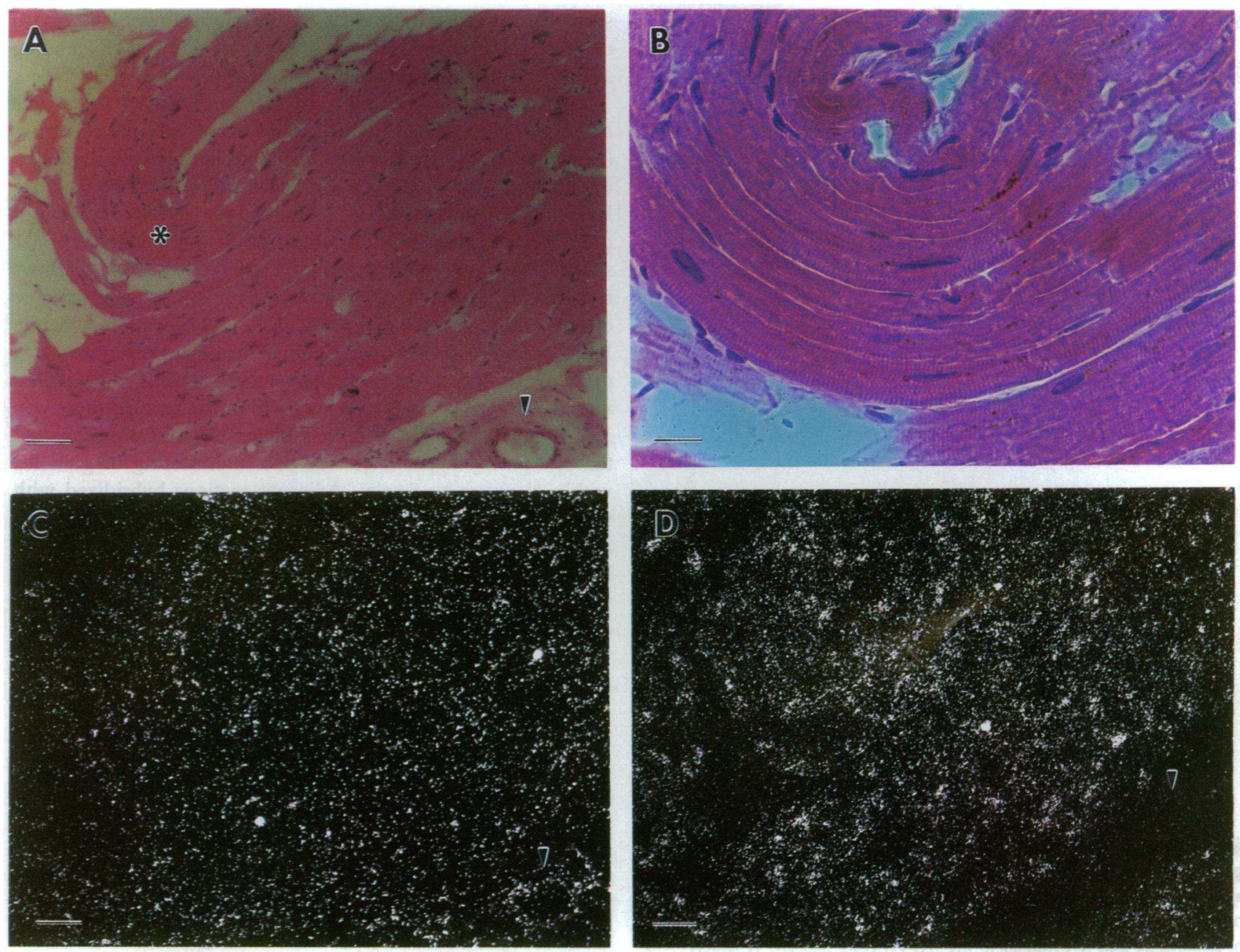

Figure 4. In situ hybridization demonstrating specificity of the cRNA probes and localizing calcium-release channel mRNA in cardiocytes. Antisense and sense ${ }^{35} S$-labeled cRNA probes were used on paraformaldehyde-fixed cardiac tissue specimens obtained from patients with cardiomyopathy. (A) Left ventricle section stained with hematoxylin and eosin containing both cardiac tissue (asterisk) and vascular smooth muscle tissue around blood vessels (arrow). (B) The area surrounding the asterisk in A is magnified further under phase contrast, to show the striations which are typical of cardiac fibers. $(C)$ Darkfield view of the same section as in A, hybridized to the IP3R antisense probe, showing that IP3R mRNA is present in vascular smooth muscle (arrow) and more importantly in cardiac myocytes. $(D)$ Darkfield view of an adjacent section hybridized to the RyR antisense probe, showing abundant RyR mRNA in cardiac fibers but not in vascular smooth muscle (arrow). Bars: $(A, C$, and $D) 80 \mu \mathrm{m} ;(B) 40$ $\mu \mathrm{m}$.

whether the tissue was obtained from ICM or IDCM patients (Fig. 3 A). Interestingly, there was an opposite trend of increased RyR mRNA levels in myopathic RV compared with normals, albeit the increase was statistically nonsignificant. The absence of a significant difference in RyR mRNA levels between normal and myopathic RV may be partly due to the varying degree of RV failure present among the patients.

More importantly, this study reports for the first time an up regulation of the IP3R mRNA levels in the ventricles of patients with end-stage CHF compared with normal patients, in contrast to other calcium channels which are down regulated (Fig. $3 \mathrm{~B}$ ). Levels of IP3R mRNA were markedly increased in the myopathic LV by $98 \%$ in ICM and by $143 \%$ in IDCM $(P<0.005$ for both), and in the myopathic RV by $80 \%$ in ICM and by $110 \%$ in IDCM $(P<0.005$ for both), compared with normal tissue. IP3R mRNA levels were also significantly up regulated in the myopathic septum by $122-124 \%(P<0.001)$, whether ICM or IDCM.
Recent studies examining protein levels of SR calciumATPase in human CHF have produced conflicting results: one reported reduction of SR calcium-ATPase protein levels by $36 \%$ in failing myocardium (29) while another did not find any difference between nonfailing and failing human myocardium (30). With regard to the present study, we sought to determine whether levels of ryanodine and IP3 binding sites were regulated during CHF similar to mRNA levels. The level of high affinity $\left[{ }^{3} \mathrm{H}\right]$ ryanodine binding sites was decreased by $30 \%$ in the myopathic LV compared with normals whereas the level of $\left[{ }^{3} \mathrm{H}\right] \mathrm{IP} 3$ binding sites remained unchanged, consistent with the data on mRNA levels of RyR, but not IP3R. Binding sites were calculated as the moles of radioligand binding per $\mathrm{mg}$ of total protein in each sample, which in effect expresses the absolute number of ryanodine and IP3 binding sites relative to much more abundant proteins that may be regulated during CHF. Direct comparison of ryanodine to IP3 binding sites reveals that the relative amount of IP3 binding sites increased $43 \%$ com- 
pared with ryanodine binding sites in the failing heart. Thus although the absolute level of IP3 binding sites was not altered during CHF, the ratio of IP3R to RyR quantified by binding studies was higher in failing versus normal human myocardium.

In the tissues comprising the myopathic LV chamber, the simultaneously reduced RyR and elevated IP3R mRNA levels argue against a universal decrease or increase in either cardiac gene expression or number of myocytes as the explanation for these findings. Recent animal studies have reproduced this finding of decreased RyR calcium-release channel expression in CHF using various animal models such as chronic doxorubicin cardiomyopathy in rabbits (24) and rapid ventricular pacing induced or spontaneous CHF in dogs (31). Our preliminary studies using rats with acute doxorubicin-induced cardiomyopathy also showed down-regulation of RyR mRNA levels, as well as up regulation of IP3R mRNA levels (32). That various processes leading to CHF manifest similar changes in calciumrelease channel regulation suggest that these changes are fundamental to the pathophysiology of CHF and not merely due to the effects of individual pharmacologic agents or entities.

It is evident that regulation of calcium channel mRNA levels vary depending on the channel type (Fig. 3, $A$ and $B$ ). The decreased expression in myopathic hearts of two channels involved in excitation-contraction coupling, the DHPR and the $\mathrm{RyR}$, implies that intracellular calcium regulation by this pathway may be impaired and could contribute to compromised cardiac contractility. Support for this concept is provided by a study which reported prolonged contractions and calcium transients in failing hearts, then proceeded to demonstrate that verapamil and ryanodine together abolished the abnormal calcium transients (18). Clinical trials have documented further deterioration of CHF in patients treated with organic calcium channel blockers including diltiazem (33) and nifedipine (34), suggesting that the excitation-contraction coupling mechanism may be already jeopardized in the myopathic heart.

The up regulation of IP3R mRNA levels and increased IP3R/RyR ratio are novel findings and may provide further insights into the molecular basis underlying different aspects of chronic CHF. For example, hypertrophy is an early response of the myocardium to the increased wall stress produced by ventricular dilatation and peripheral vasoconstriction (23), and this enduring response manifested by the gross biventricular and microscopic myocyte hypertrophy and enlarged pleomorphic nuclei which are characteristic of explanted hearts from patients with end-stage CHF (35). Multiple growth factors have been shown to cause cardiac myocyte hypertrophy with DNA replication (polyploidy) in in vitro studies (36), and some of these factors exert their effects via the IP3/calcium signaling pathway, such as angiotensin II $(37,38)$ or endothelin $(36,39)$. Increased IP3R expression in ventricular myocytes during CHF is consistent with the up regulation of a signaling pathway mediating the hypertrophic response.

The IP3R could participate in regulating contractility in the failing heart by analogy to its role in controlling smooth muscle contraction via pharmacomechanical coupling $(10,12)$. CHF is a disorder of the circulation characterized by elevated neurohormonal activity (23). Studies using intracoronary infusions of adrenergic agonists in patients with CHF have demonstrated both $\beta$-adrenergic receptor-mediated lusitropy and $\alpha$-adrenergic receptor-mediated inotropy in such patients (40). Such modulation of contractility by adrenergic agents can be carried out through the IP3R-mediated intracellular calcium release $(10$,
41), with up regulation of IP3R as a mechanism to increase sensitivity in the failing myocardium.

In addition to regulating contractility and facilitating hypertrophy in the failing myocardium, the IP3/calcium signaling pathway may play a pathological role in cardiac arrhythmogenesis (4). Delayed afterpotentials in hypertrophied and failing myocardium have been attributed to abnormal transient inward currents which occur during diastole; if large enough, these afterdepolarizations can reach threshold and trigger arrhythmias (42). Development of high myoplasmic calcium level during diastole $(>500 \mathrm{nM})$ due to intracellular calcium oscillations appeared to induce this inward current $(43,44)$. Recent data from skinned cardiac fibers demonstrated that IP3 enhanced such calcium oscillations from the SR (45). Thus, the increased IP3R expression in myocardium of patients with end-stage CHF could potentially explain why these patients are so susceptible to arrhythmias.

In view of the decreased expression in cardiomyopathic tissue of the calcium channels involved in excitation-contraction coupling, the alternative pathway of regulating intracellular calcium via the IP3R calcium-release channel may prove to be a significant compensatory mechanism in the failing human heart. Therapy designed to enhance pharmacomechanical coupling by targeting the IP3R might prove efficacious. However, this speculation should be tempered as we did not examine inositol polyphosphate hydrolysis per se in our samples by membrane bound phospholipase $\mathrm{C}$, which in turn is dependent upon Gprotein coupled receptors, tyrosine kinase coupled receptors, and mechanical deformation for its activation $(9,10,37,38)$.

In summary, differential regulation of calcium-release channel mRNA levels occurs during end-stage CHF according to channel type. RyR mRNA levels in the myopathic LV and septum is down regulated compared to normal. In contrast, there is a consistent trend of increased IP3R mRNA levels in failing human myocardium compared to normal. Such an alteration in calcium handling may be a molecular mechanism underlying impaired excitation-contraction coupling, enhanced pharmacomechanical coupling, compensatory hypertrophy, and increased arrhythmia susceptibility which are observed in progressive myocardial dysfunction. These insights into the molecular basis of CHF should provide new directions for future diagnostic and therapeutic approaches.

\section{Acknowledgments}

We thank Drs. Valentin Fuster and Richard Gorlin for helpful comments and for support, Dr. Alan Gass and Mary Courtney, R.N., for providing clinical data, Dr. Steven Lansman for providing access to the explanted hearts, and Dr. Luyi Sen for providing three of the normal heart samples.

This work was supported in part by grants from the National Institutes of Health (NS-29814) and the American Heart Association (to A. R. Marks). A. R. Marks is a Bristol-Meyers/Squibb Established Investigator of the American Heart Association. L. O. Go is an American College of Cardiology/Merck Research Fellow.

\section{References}

1. Parmley, W., K. Chatterjee, G. Francis, B. Firth, and R. Kloner. 1991 Congestive heart failure - new frontiers. West. J. Med. 154:427-441.

2. McKee, P., W. Castelli, P. McNamara, and W. Kannel. 1971. The natural history of congestive heart failure: the Framingham Study. N. Engl. J. Med. 285:1441-1446.

3. Fleischer, S., and M. Inui. 1989. Biochemistry and biophysics of excitationcontraction coupling. Annu. Rev. Biophys. Chem. 18:333-364. 
4. Callewaert, G. 1992. Excitation-contraction coupling in mammalian cardiac cells. Cardiovasc. Res. 26:923-932.

5. Fabiato, A. 1983. Calcium-induced release of calcium from the cardiac sarcoplasmic reticulum. Am. J. Physiol. 245:C1-C14.

6. Furuichi, T., S. Yoshikawa, A. Miyawaki, K. Wada, N. Maeda, and K. Mikoshiba. 1989. Primary structure and functional expression of the inositol 1,4,5 trisphosphate-binding protein P400. Nature (Lond.). 342:32-38.

7. Marks, A., P. Tempst, C. Chadwick, L. Riviere, S. Fleischer, and B. NadalGinard. 1990. Smooth muscle and brain inositol 1,4,5-trisphosphate receptors are structurally and functionally similar. J. Biol. Chem. 265:1-4.

8. Moschella, M., and A. Marks. 1993. Inositol 1,4,5-trisphosphate receptor expression in cardiac myocytes. J. Cell Biol. 120:1137-1146.

9. Berridge, M., and R. Irvine. 1989. Inositol phosphates and cell signalling. Nature (Lond.). 341:197-205.

10. Berridge, M. 1993. Inositol trisphosphate and calcium signalling. Nature (Lond.). 361:315-325.

11. Ehrlich, B., and J. Watras. 1988. Inositol 1,4,5-trisphosphate activates a channel from smooth muscle sarcoplasmic reticulum. Nature (Lond.). 336:583586.

12. Hathaway, D., K. March, J. Lash, L. Adam, and R. Wilensky. 1991 Vascular smooth muscle - a review of the molecular basis of contractility. Circu lation. 83:382-390.

13. Somlyo, A., M. Bond, A. Somlyo, and A. Scarpa. 1985. Inositol trisphosphate-induced calcium release and contraction in vascular smooth muscle. Proc Natl. Acad. Sci. USA. 82:5231-5235.

14. Marks, A., P. Tempst, K. Hwang, M. Taubman, M. Inui, C. Chadwick, S. Fleischer, and B. Nadal-Ginard. 1989. Molecular cloning and characterization of the ryanodine receptor/junctional channel complex cDNA from skeletal muscle sarcoplasmic reticulum. Proc. Natl. Acad. Sci. USA. 86:8683-8687.

15. Otsu, K., H. Willard, V. Khanna, F. Zorzato, N. M. Green, and P.-H. MacLennan. 1990. Molecular cloning of cDNA encoding the $\mathrm{Ca} 2+$ release channel (ryanodine receptor) of rabbit cardiac muscle sarcoplasmic reticulum. J. Biol. Chem. 265:13472-13483.

16. Takeshima, H., S. Nishimura, T. Matsumoto, H. Ishida, K. Kangawa, N. Minamino, H. Matsuo, M. Ueda, M. Hanaoka, T. Hirose, and S. Numa. 1989. Primary structure and expression from complementary DNA of skeletal muscle ryanodine receptor. Nature (Lond.). 339:439-445.

17. Chadwick, C., A. Saito, and F. S. 1990. Isolation and characterization of the inositol trisphosphate receptor from smooth muscle. Proc. Natl. Acad. Sci. USA. 87:2132-2136.

18. Gwathmey, J., L. Copelas, R. McKinnon, F. Schoen, M. Feldman, W. Grossman, and J. Morgan. 1987. Abnormal intracellular calcium handling in myocardium from patients with end-stage heart failure. Circ. Res. 61:70-76.

19. Mercadier, J., A. Lompre, P. Duc, K. R. Boheler, J. B. Fraysse, C. Wisnewsky, P. D. Allen, M. Komajda, and K. Schwartz. 1990. Altered sarcoplasmic reticulum $\mathrm{Ca} 2+-\mathrm{ATPase}$ gene expression in the human ventricle during end-stage heart failure. J. Clin. Invest. 85:305-309.

20. Takahashi, T., P. Allen, A. Marks, A. Denniss, F. Schoen, W. Grossman, J. Marsh, and S. Izumo. 1992. Altered expression of genes encoding the $\mathrm{Ca} 2+$ regulatory proteins in the myocardium of patients with end-stage heart failure: Correlation with expression of the Ca2+-ATPase gene. Circ. Res. 71:1357-1365.

21. Arai, M., N. Alpert, D. MacLennan, P. Barton, and M. Periasamy. 1993. Alterations in sarcoplasmic reticulum gene expression in human heart failure: a possible mechanism for alterations in systolic and diastolic properties of the failing myocardium. Circ. Res. 72:463-469.

22. Brilliantes, A., P. Allen, T. Takahashi, S. Izumo, and A. Marks. 1992. Differences in cardiac calcium release channel (ryanodine receptor) expression in myocardium from patients with end-stage heart failure caused by ischemic versus dilated cardiomyopathy. Circ. Res. 71:18-26.

23. Packer, M. 1992. Pathophysiology and treatment of chronic heart failure. Lancet. 340:88-95.

24. Dodd, D., J. Atkinson, R. Olson, S. Buck, B. Cusack, S. Fleischer, and R. Boucek Jr. 1993. Doxorubicin cardiomyopathy is associated with a decrease in calcium release channel of the sarcoplasmic reticulum in a chronic rabbit model. J. Clin. Invest. 91:1697-1705.

25. Benevolensky, D., I. Moraru, and J. Watras. 1994. Micromolar calcium decreases affinity of inositol trisphosphate receptor in vascular smooth muscle. Biochem. J. 299:631-636.

26. Kentish, J., R. Barsotti, T. Lea, I. Mulligan, J. Patel, and M. Ferenczi. 1990 Calcium release from cardiac sarcoplasmic reticulum induced by photorelease of calcium or Ins(1,4,5)P3. Am. J. Physiol. 258:H610-H615.

27. Nosek, T., M. Williams, S. Ziegler, and R. Godt. 1986. Inositol trisphosphate enhances calcium release in skinned cardiac and skeletal muscle. Am Physiol. 250:C807-C811.

28. Nakagawa, T., H. Okano, T. Furuichi, J. Aruga, and K. Mikoshiba. 1991. The subtypes of the mouse inositol 1,4,5-trisphosphate receptor are expressed in a tissue-specific and developmentally specific manner. Proc. Natl. Acad. Sci. USA. 88:6244-6248.

29. Hasenfuss, G., H. Reinecke, R. Studer, M. Meyer, B. Pieske, J. Holtz, C. Holubarsch, H. Posival, H. Just, and H. Drexler. 1994. Relation between myocardial function and expression of sarcoplasmic reticulum $\mathrm{Ca} 2+$-ATPase in failing and nonfailing human myocardium. Circ. Res. 75:434-442.

30. Movsesian, M., M. Karimi, K. Green, and L. Jones. 1994. $\mathrm{Ca}^{2+}$-transporting ATPase, phospholamban and calsequestrin levels in nonfailing and failing human myocardium. Circulation. 90:653-657.

31. Cory, R., L. McCutcheon, M. O'Grady, A. Pang, J. Geiger, and P. O'Brien. 1993. Compensatory downregulation of myocardial Ca channel in SR from dogs with heart failure. Am. J. Physiol. 264:H926-H927.

32. Handa, K., M. Moschella, B. Fyfe, and A. Marks. 1993. Regulation of calcium channel expression during heart failure. Circulation. 88(suppl I):I-624. (Abstr.)

33. Goldstein, R., S. Boccuzzi, D. Cruess, and S. Nattel. 1991. Diltiazem increases late-onset congestive heart failure in post-infarction patients with early reduction in ejection fraction. Circulation. 83:52-60.

34. Elkayum, V., J. Amin, A. Mehra, J. Vasquez, L. Weber, and S. Rahimtoola. 1990. A prospective, randomized double-blind cross-over study to compare the efficacy and safety of chronic nifedipine therapy with that of isosorbide dinitrate and their combination in the treatment of chronic congestive heart failure. Circulation. 82:1954-1961.

35. Tazelaar, H., and W. Edwards. 1992. Pathology of cardiac transplantation: recipient hearts (chronic heart failure) and donor hearts (acute and chronic rejection). Mayo Clin. Proc. 67:685-696.

36. Chien, K., K. Knowlton, H. Zhu, and A. Chien. 1991. Regulation of cardiac gene expression during myocardial growth and hypertrophy: molecular studies of an adaptive physiologic response. FASEB (Fed. Am. Soc. Exp. Biol.) J. 5:3037-3046.

37. Sadoshima, J., and S. Izumo. 1993. Signal transduction pathways of angiotensin II induced c-fos gene expression in cardiac myocytes in vitro: roles of phospholipid-derived second messengers. Circ. Res. 73:424-438.

38. Sadoshima, J., Y. Xu, H. Slayter, and S. Izumo. 1993. Autocrine release of angiotensin II mediates stretch-induced hypertrophy of cardiac myocytes in vitro. Cell. 75:977-984.

39. Lovenberg, W., and R. Miller. 1990. Endothelin: a review of its effects and possible mechanisms of action. Neurochem. Res. 15:407-417.

40. Colucci, W. 1993. In situ assessment of $\alpha$ - and $\beta$-adrenergic responses in failing human myocardium. Circulation. 87(suppl VII):VII63-VII67.

41. Otani, H., H. Otani, and D. Das. 1988. $\alpha 1$-Adrenoreceptor-mediated phosphoinositide breakdown and inotropic response in rat left ventricular papillary muscles. Circ. Res. 62:8-17.

42. Aronson, R., and Z. Ming. 1993. Cellular mechanisms of arrhythmias in hypertrophied and failing myocardium. Circulation. 87(suppl VII):VII76-VII83.

43. Colquhoun, D., E. Neher, H. Reuter, and C. Stevens. 1981. Inward current channels activated by intracellular Ca in cultured cardiac cells. Nature (Lond.). 294:752-754.

44. Orchard, C., D. Eisner, and D. Allen. 1983. Oscillations of intracellular $\mathrm{Ca}^{2+}$ in mammalian cardiac muscle. Nature (Lond.). 304:735-738.

45. Zhu, Y., and T. Nosek. 1991. Inositol trisphosphate enhances $\mathrm{Ca}^{2+}$ oscillations but not $\mathrm{Ca}^{2+}$-induced $\mathrm{Ca}^{2+}$ release from cardiac sarcoplasmic reticulum. Pflugers Arch. 418:1-6. 